\title{
COMMENTARY
}

\section{Expert Perspectives on COVID-19 Vaccination for People Living with Multiple Sclerosis}

Robert K. Shin $\cdot$ Kottil W. Rammohan $\cdot$ Mitzi J. Williams

Received: June 29, 2021 / Accepted: July 8, 2021 / Published online: August 4, 2021

(C) The Author(s) 2021

\section{ABSTRACT}

COVID-19 vaccines are safe for people living with MS on or off disease-modifying therapies and are important for the prevention of COVID19. Antibody responses for individuals on certain DMTs may be diminished, however, T-cell responses may be preserved in those

Electronic supplementary material The online version of this article (https://doi.org/10.1007/s40120021-00266-z) contains supplementary material, which is available to authorized users.

R. K. Shin (殴

MedStar Georgetown University Hospital, 3800 Reservoir Rd NW, Washington, DC 20007, USA e-mail: Robert.K.Shin@gunet.georgetown.edu

K. W. Rammohan

University of Miami Miller School of Medicine, Miami, FL, USA

e-mail: krammohan@med.miami.edu

M. J. Williams

Joi Life Wellness Group, Atlanta, GA, USA

e-mail: drmitzi@joilifewellness.com individuals. Data are lacking regarding optimal timing of vaccinations, and delaying diseasemodifying therapies may increase the risk of disease activity and progression. In this perspective podcast, the authors recommend COVID-19 vaccination as soon as possible, regardless of timing considerations, in most cases. 


\section{Graphical Plain Language Summary:}

\section{Expert Perspectives on COVID-19 Vaccination for People Living with Multiple Sclerosis}

Robert K Shin, Kottil W Rammohan, Mitzi J Williams

In this podcast article, multiple sclerosis (MS) specialists offer

their experience and perspectives on coronavirus disease

2019 (COVID-19) vaccination for people living with MS.

COVID-19 vaccines are:
Safe for people living with MS on or off disease-modifying
therapies (DMTs)
important for the prevention of COVID-19
expected to elicit an immune response in individuals on
DMTs, consistent with experience with routinely utilized
vaccines like seasonal influenza

What are the considerations for COVID-19 vaccination in people living with MS on DMTs?

\begin{tabular}{|c|c|}
\multicolumn{2}{|c|}{ in people living with MS on DMTs? } \\
\hline \multicolumn{2}{|c|}{ Vaccinations lead to both B and T cell responses } \\
\hline $\begin{array}{c}\text { Antibody responses for } \\
\text { individuals on certain DMTs } \\
\text { may be diminished }\end{array}$ & $\begin{array}{c}\text { However, T cell responses } \\
\text { may be preserved } \\
\text { in those individuals }\end{array}$ \\
\hline
\end{tabular}

\section{Should we consider pausing/adjusting the timing of certain} DMTs to maximize antibody responses?

Data is lacking regarding optimal timing of vaccinations, and delaying DMTs may increase the risk of disease activity and progression

We recommend COVID-19 vaccination as soon as possible, regardless of timing considerations, in most cases

\section{COVID-19 vaccination is critical.}

High-efficacy therapies prevent MS disease progression.

Balance MS treatment and vaccination scheduling.

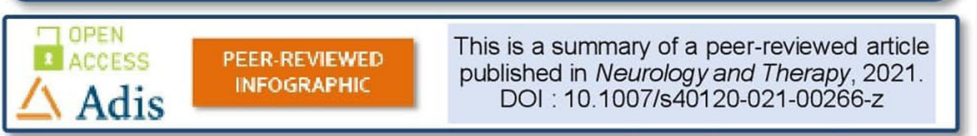

This plain language summary represents the opinions of the authors. For a full list of declarations, including funding and author disclosure statements, please see the full text online. (C) The authors, CC-BY-NC 2021 Prepared by Meredith Whitaker, PhD, Alphabet Health. Plain language services were funded by Novartis.

The original authors of the manuscript reviewed this summary 
Keywords: B-cell-targeting therapy; Coronavirus; COVID-19; Disease modifying therapy; Multiple sclerosis; Patient education; SARSCoV-2; Vaccines

\section{Key Summary Points}

COVID-19 vaccines are safe for people living with multiple sclerosis (MS) on or off disease-modifying therapies (DMTs) and are important for the prevention of coronavirus disease 2019 (COVID-19).

Antibody responses for individuals on certain DMTs may be diminished, however, T-cell responses may be preserved in those individuals.

Data are lacking regarding optimal timing of vaccinations, and delaying DMTs may increase the risk of disease activity and progression.

In this perspective podcast the authors recommend COVID-19 vaccination as soon as possible, regardless of timing considerations, in most cases.

\section{DIGITAL FEATURES}

This article is published with digital features, including a podcast audio file and graphical plain language summary to facilitate understanding of the article. To view digital features for this article go to https://doi.org/10.6084/ m9.figshare.14931969.

\section{PODCAST TRANSCRIPT}

\section{INTRODUCTION}

\section{Mitzi Williams:}

Welcome to our podcast discussion about COVID-19 [coronavirus disease 2019] vaccination and multiple sclerosis (MS). My name is
Dr. Mitzi Joi Williams, and I'm a board-certified neurologist and MS specialist at the Joi Life Wellness MS Center in Atlanta, Georgia. There've been many challenges that we've seen over the past year with the advent of the COVID-19 pandemic. Initially, there were many concerns related to our disease-modifying therapies and risks for COVID-19, but now that vaccination has become more widely available, are there clinical considerations that we want to think about when counseling our patients who need to receive COVID-19 vaccination but also have multiple sclerosis?

Mitzi Williams:

I'm very excited to have two wonderful experts here with me today to talk about their experience and to answer some of these questions, and hopefully provide some general guidance and discussion around the information we have available. I will have my colleagues Dr. Rammohan and Dr. Shin introduce themselves.

Kottil Rammohan:

Thank you, Dr. Williams. My name is Dr. Kottil Rammohan. I have been involved with MS ever since I finished my neurology residency in 1976.

Bob Shin:

I'm Bob Shin. I'm a neurologist at MedStar Georgetown University Hospital. I do MS and neuro-ophthalmology, and I direct the Georgetown MS and Neuroimmunology Center.

\section{COVID-19 VACCINES}

Mitzi Williams:

Dr. Shin, can you start out by telling us what vaccines are available here in the USA and a little bit about the dosing for those vaccines?

Bob Shin:

Sure. Well, one thing to remember is that different countries are using different vaccines; in the USA, we have three safe and very effective vaccine options [1]. The first two that we had were Pfizer-BioNTech as a collaboration (NCT04368728) [2], and then there's a Moderna vaccine (NCT04470427) [3], and both of these vaccines are mRNA vaccines. So they don't use any infectious particles. They just send 
instructions to help teach the immune system how to fight COVID-19. Then, more recently, a third vaccine was added to our toolbox and that's the Johnson \& Johnson/Janssen (J\&J/ Janssen) vaccine, which is a different technique using a viral vector (NCT04505722) [4]. In this case, again not using COVID-19 in any way, but using an otherwise harmless virus to deliver those instructions. Now the Pfizer-BioNTech and the Moderna vaccines-the mRNA vaccines-are two jabs, 3 or 4 weeks apart, depending on the vaccine. The J\&J vaccine is a one-shot deal.

Mitzi Williams:

Dr. Rammohan, any additional thoughts about the mRNA vector, which is a fairly new type of way to deliver vaccines, although it's been around for a long time; but it's new in terms of us being able to use it.

Kottil Rammohan:

That's exactly correct. The mRNA vaccine has been around in oncology for vaccination against tumor antigens [5], but as a technique for using against infectious diseases, this is a relatively new technique. The same thing is true also for the adenovirus vector vaccines; as Dr. Shin mentioned, the J\&J vaccine is an adenovirus vector. The vaccine that is used by pretty much most of the world is the AstraZeneca vaccine [6] that was developed at Oxford (NCT04516746) [7]. That's also an adenovirus vector.

Kottil Rammohan:

The other point that I want to make is this is what is called a subunit vaccine. What you mean by that is that it doesn't take the whole virus; this is coding just for the spike protein of the virus. Now, the spike protein of the virus itself is two separate peptides with a link point. There's an S1 spike protein and an S2 spike protein. S1 is the protein with which the virus docks onto its receptor, which is ACE2 [angiotensin-converting enzyme 2] and the receptor that attaches the virus to its host cell [8].

Kottil Rammohan:

So the strategy used here is that you create antibodies to the S1 domain mainly [9], and that results in protection, and the virus can no longer dock to its receptor and cause infections. So it is a very effective strategy, just a single part of the virus. You don't give the entire genome like we do in the flu vaccine [10]. This is just a very targeted approach, incredibly effective in its final outcome.

Mitzi Williams:

Absolutely. I think that's one of the great things that has come out of the pandemic is that there really has been a lot of amazing science and a lot of collaboration, very quickly that we usually aren't able to see.

\section{VACCINATION CONSIDERATIONS FOR PEOPLE LIVING WITH MS}

\section{Mitzi Williams:}

So you mentioned, Dr. Rammohan, the flu vaccines. So just switching gears a little bit, let's think about the recommendations that we give our patients for other vaccinations. We don't yet have all of the scientific trials about COVID19 vaccine and people with MS. Obviously, people are developing real-world data sets as we go along, but we still have a long way to go.

Mitzi Williams:

When we think about the flu vaccine, we generally recommend that all of our patients get flu vaccine regardless as to what treatment they're taking and really regardless as to the timing [11-13]. I don't recall going through and talking to my patients and recommending that they pause their flu vaccine or not get their vaccine at certain times because of their treatment. But this is a concern that many people have had, that many of our colleagues have had with the advent of the COVID-19 vaccination, particularly some of our patients who are taking B-cell therapies. So what are your recommendations, Dr. Shin, for your patients about receiving the flu vaccine? Tell us a little bit about some of the considerations for those receiving COVID-19 vaccine and what are some of the concerns about receiving those for those who are on anti-B-cell therapy?

Bob Shin:

Well, I think it's very interesting to go back and think about the good old days. We didn't know about COVID-19 and we didn't have a worldwide pandemic to be afraid of. There had been actually data looking at the effectiveness 
of things like flu vaccines and other, if you will, routine vaccines in people living with MS who were on a variety of different MS therapies. In general, the studies showed either that the MS therapies did not really have much of an effect in terms of suppressing immune response to vaccines, or if there was an effect, it seemed to be relatively modest. And in no case did those kinds of concerns outweigh the mandate of really making sure our patients are protected from influenza or any other infection. And so before COVID-19, I'm going to be honest, I didn't really spend a lot of time thinking about it. As you already expressed, I said, "Get the flu shot." Every year, we would remind our patients to get vaccinated.

Bob Shin:

I remember earlier in training, I remember a "debate" where people said, "Well, I worry that if I stimulate the immune system by administering a vaccine I might activate their MS. Maybe we should not do that." I think that debate was long ago answered, that there's no evidence that vaccinating our patients with any vaccine is harmful from the MS standpoint, and the benefit of vaccination always greatly outweighed any other potential issues. So that really was my practice before the COVID-19 crisis, and to some degree, is still how I'm trying to manage my patients.

Mitzi Williams:

Absolutely. And I think, again, I have a very similar practice as we discussed.

Mitzi Williams:

And then the other question that I'd like to raise for Dr. Rammohan, is when we think about immunity, right, we know that our patients do develop some type of immune response, even though it may be blunted with some of our B-cell therapies, but there also is a T-cell immune response that's important to having protection $[14,15]$. So let's say theoretically, if our patients don't develop a good B-cell response, if they are depleted, does that necessarily mean they're not protected? Or what does that mean clinically?

Kottil Rammohan:

That's a very good point. So we know that if a person has congenital agammaglobulinemia where they have no $\mathrm{B}$ cells, there are case reports of these patients getting COVID-19 infection and making an uneventful recovery [16-18].

Kottil Rammohan:

Now, after they recover, if you test their serum for antibody, as would be expected, these people do not have any detectable antibody, but they made a completely uneventful recovery. Some people feared that these people would be at great risk and gave them antibody as part of the treatment. But there are also case reports of people who never received IVIG [intravenous immunoglobulin] or immunoglobulin specific for COVID, and made a perfectly complete recovery [16].

Kottil Rammohan:

And that's sort of been the experience that we went through. In fact, if you recall, in the beginning of the pandemic in or around February/March of 2020, the MS Society put in place recommendations [19], which were not based on evidence because we simply didn't have any evidence; and the recommendation was really scary for people who were on antiCD20 therapy, saying, "Be careful."

Kottil Rammohan:

But, fortunately a lot of our MS patients, in fact most of our MS patients, did quite well and handled the COVID pandemic well. And if you look at COViMS.org, the registry that captures MS patients who got COVID, as of today, there are probably over 3200 patients in that registry, but only about 90 deaths occurred, fortunately, and every one of those deaths occurred in people with significant amount of disability [20].

Kottil Rammohan:

So from the standpoint of the infection itself, not having B cells does not seem to be a significant problem. Now that said, the opposite is also true-that if you don't have B cells and you got the vaccine, you may not mount an adequate immune response. And there is a lot of debate today as to who will produce antibody in the course of anti-CD20 therapy, and who will not produce any antibody. And basically this may have something to do with the timing of when you give the vaccine in relation to this cycle of when they get their anti-CD20 therapy, or it may have factors that are beyond that. We don't really fully understand it $[21,22]$. 


\section{Kottil Rammohan:}

In fact, there was a very nice presentation at the American Academy of Neurology on a very large number of patients, which found that after vaccination patients on ocrelizumab do not mount an antibody response with the standard Roche platform assay compared to people on other therapies; there was a highly, highly significant $p$ value in terms of the fact that people on ocrelizumab did not make antibodies compared to people on other therapies [23].

Kottil Rammohan:

What was interesting in that same study was that these investigators looked at the T-cell response to the vaccine and found that the majority of people who did not make antibody made a T-cell response. And normally when we test, we do not test for the T-cell part. We only test for the antibody part, and you may walk away thinking that giving immunization to patients on B-cell depletion is not worthwhile. And that's not appropriate because these people do have protection, they have the T-cell-mediated part of the protection.

Mitzi Williams:

That segues and really answers one of the big questions when we talk about guidelines, right? There are a lot of guidelines that have been released and updated every couple of months by our different societies, particularly the MS Society, the Federation. And so when we look at these guidelines, they are based on expert opinion, but recommend kind of these ways of timing the vaccine that may not really be feasible in clinical practice.

Mitzi Williams:

So there are some recommendations that if someone is on an anti-B-cell therapy, that they wait at least 12 weeks after their last infusion to try to get their vaccine to possibly mount the best immune response. I would say that for my patient population, that I recommend that people get vaccinated when they can get vaccinated.

Mitzi Williams:

I live in a State [USA] where vaccination was very slow and hard to get to at times. And so we didn't necessarily have the luxury of saying, "Well, we're going to plan on getting your vaccine 3 months from now, or this time from now." And we really have recommended that people get vaccinated as soon as they can with whatever vaccine they can be vaccinated with. So are the recommendations similar for your practices or do you try to time the vaccination for the best B-cell response? We'll start with Dr. Shin.

Bob Shin:

Well, first of all, let me add something to what Dr. Rammohan had said earlier about summarizing the limited knowledge that we have about vaccination response with MS therapies. I think we should be honest and admit that there's a lot that we don't know about how people benefit from vaccines. We certainly believe that it's a complex process that involves both $\mathrm{B}$ and $\mathrm{T}$ cells.

Bob Shin:

And I think we should also be honest and say that there have been surprises during the pandemic, as we've observed the responses of people living with MS on different therapies, in terms of population responses to vaccination. For example, already alluded to, the blunted antibody response that's observed in individuals who are on B-cell therapies, I think was interesting. Part of what was interesting about what was presented was certainly, as pointed out, that T-cell responses can be preserved, but I think also the observation that the antibody titer response varied based on what kind of assay was being used. Some assays were able to identify response and other assays were not.

Bob Shin:

And that's really just looking at B-cell therapies in general, where in other contexts, we had already known that antibody titers tend to be depressed in patients on B-cell therapies to really any vaccine. And although we've known about this probably for decades at this point, it was never a reason to not vaccinate. We still believe that vaccines benefited patients who were on B-cell therapies.

Bob Shin:

I think a more recent surprise was a small report suggesting that patients on S1P [sphingosine 1-phosphate] agents had very markedly reduced antibody titers [22], whereas previous to this crisis, patients on S1P agents again may have had a slightly blunted response, but we 
still believe that they were still benefiting from the vaccinations. I think a third surprise was that maybe a medication like cladribine, which we believe acts by suppressing the B and T cells, was later shown to actually not really affect antibody responses, that the antibody titers were quite robust in patients receiving them [22].

Bob Shin:

So I think we should just say that there's a lot that we don't know, and it's almost impossible to predict how a patient will respond to a vaccine just based on our limited understanding of the mechanisms of action. We focus on antibody titers because it's something that we can actually measure. The actual question you asked was on vaccine timing. Early on in the pandemic, especially, there were many different statements that were made by many different individuals that were published in the literature, on blogs, and they were based on very limited information and often were not consistent with each other. But I think really the focus is shifting to a different statement with the recommendations, with the National MS Society stating that it was felt that for individuals, clinical considerations and the mandate to get vaccinated should really take precedence over timing considerations.

Bob Shin:

I'm going to say that in my own personal practice, especially early on when it was more difficult to get the vaccine, my advice was if you have the opportunity to get vaccinated, please get vaccinated. And even though there's been a little bit more availability, that advice-at least for my patients-still stands.

\section{ADVERSE EVENTS ASSOCIATED WITH VACCINATION, PATIENT EDUCATION, AND DISPELLING MYTHS}

\section{Mitzi Williams:}

I agree with everything that's been said. And so, switching gears and talking about some of the anxiety for our patients, there are two more topics that I think we should cover. And one of them being potential side effects of the vaccine as well as dispelling myths about the vaccine.

Mitzi Williams:

There are many patients of mine who've received vaccination and I recommended vaccination, but there are still some who are very concerned about long-term side effects, who are concerned about some of the side effects that we've heard about such as transverse myelitis [24]. There've been a couple of cases of GBS [Guillain-Barré syndrome] [25, 26]. And then with the J\&J there were six reported cases of blood clotting.

Mitzi Williams:

These side effects so far are very rare compared to the number of people who've been vaccinated. Looking at the risks versus the benefits for the majority of our patients, the benefits of being vaccinated will far outweigh the risks. Are there any thoughts that you all have, or counseling that you give your patients when they ask about the side effects or longterm efficacy of the vaccine?

Kottil Rammohan:

You mentioned GBS $[25,26]$; in the trial for the J\&J vaccine, they had one patient with GBS but they also found one patient in the placebo arm [4].

Kottil Rammohan:

Then later, in February of 2021 this year, Pfizer BioNTech also reported a patient with GBS [27]. After the rollout of the vaccine, we really haven't seen cases of GBS pop up here, there, and everywhere. And so this is not a major concern, but it is something that we worried about.

Kottil Rammohan:

You mentioned acute transverse myelitis, and there's a very nice published review of this which looked at all published acute transverse myelitis, and this was from 21 different countries; there were 43 cases of acute transverse myelitis from COVID-19 infection and only three from vaccination [24]. And that was during the trial for the AstraZeneca, the trial that put this vaccine on the market [7]. So, what is interesting is that one out of those three cases was actually an MS patient who was not previously diagnosed with MS. But when they actually studied the patient, they found that the 
patient had longstanding evidence of MS and that it was just unmasked during the COVID-19 vaccination in this individual.

\section{Kottil Rammohan:}

So, is this unmasking of a latent problem due to the vaccination? We don't really know the pathogenesis involved. But as you can imagine, three acute transverse myelitis cases is a tiny number compared to the millions of people who have received this vaccine. There is also this issue of blood clots that you mentioned [28]: six cases from the J\&J vaccine, but a few additional cases were identified when they put out the bulletin [29]. Bell's Palsy has been reported, and there was a review about this [30].

Kottil Rammohan:

The bottom line about all this is whether it is GBS, acute transverse myelitis, blood clots, or Bell's Palsy, these are extremely, extremely rare occurrences and that when weighing the benefits versus the risks, the benefits far outweigh the risk.

Bob Shin:

I really try to give a similar message to my patients who are concerned about complications from the vaccine.

Bob Shin:

I think that there is naturally fear whenever anything is new, and so we tend to focus quite a bit on rare side effects, but I think it's also important to emphasize to our patients what's the alternative.

Bob Shin:

In the USA, 600,000 Americans have died from this virus. It's hard to actually emphasize or accurately talk about how much the risk-benefit ratio tilts in favor of vaccination.

Bob Shin:

I reassure my patients that these vaccines are safe and whatever potentially small risks there might be are just tremendously outweighed by the benefit to receiving the vaccine. I think we still have a ways to go in reassuring not just our patients and our peers, but maybe the entire population that there is really no question, everybody needs to get vaccinated against COVID-19.

Mitzi Williams:

And in my experience, it really is all about how I frame it for my patients. I know one of the biggest concerns is the speed at which the vaccine was developed, but I really look at it as a triumph of science. It was kind of a perfect storm where mRNA vaccines have been worked on for a very long time and used in other areas, as Dr. Rammohan stated. I also emphasize the very large number of people who were involved in these clinical trials, 20 in total, and in some cases close to 30,000 people were involved [2-4]. And so I really go through the science with my patients, which is reassuring for them, and then I also talk to them about the benefits of being vaccinated versus getting COVID-19. The other thing to emphasize is not only can it be a deadly disease, but that for many it can be a chronic disease. There are people that have very long-lasting effects and other sequelae, such as heart failure and lung damage. So that shared decision-making is very important. We definitely try to communicate with our patients as much as possible and direct them to trusted sources of information.

\section{CONCLUDING REMARKS}

\section{Mitzi Williams:}

Some of the big takeaways that I've gotten from this amazing conversation has been that the COVID-19 vaccination, that there are many vaccinations being offered across the world. The three that we have here in the USA, the Pfizer, the Moderna, and the J\&J vaccine, are very safe and very effective for our patients. Certainly there are some potential side effects, but they're rare. And for most of our patients, the potential benefits of vaccination outweigh the risks of side effects.

Kottil Rammohan:

I think the emphasis should be go get the vaccine [31]. And I also want to stress that if a patient has previously had COVID, that does not guarantee that they're immune from another attack of COVID. We have seen COVID happen in February and then once again in May in the same patient. And so everybody, including those patients who had COVID previously, should be encouraged to get the vaccine.

Kottil Rammohan: 
And then I am more on the conservative side, more conservative than the CDC [US Centers for Disease Control and Prevention] I would say because I tell them even though you have been fully vaccinated, I want you to still practice social distancing, hand-washing, and mask-wearing because you hear about variants that might breakthrough. Until this pandemic is over, practice good prophylaxis.

Bob Shin:

The only thing that I might want to add is when it comes to our MS treatment options and questions about whether we should delay treatment or perhaps avoid initiating certain treatments or switch people from one treatment to another out of concerns about vaccine efficacy, I would emphasize that we already have known risks of under-treating MS, which is that if we either delay treatment or use less effective therapies in patients with active disease, those decisions will result in more relapses, more MRI [magnetic resonance imaging] lesions, and more disability over time.

Bob Shin:

All evidence so far has suggested that all of our MS patients benefit from vaccination regardless of what MS therapy they're on. And, therefore, at least in my opinion, we should continue to stay the course in terms of remembering our primary mission of reducing the impact of MS on our population.

Mitzi Williams:

Absolutely. We recommend our patients continue to protect themselves. We know what MS does and we need to treat MS and making sure that our patients remain free of as much disability as possible and also protecting them against COVID-19.

You can listen to more podcasts by subscribing to Adis Rapid + podcast with your preferred podcast provider, or by visiting the website. A full list of declarations, including funding and author disclosure statements, can also be found on the journal website.

\section{ACKNOWLEDGEMENTS}

Funding. The journal's Rapid Service Fee was funded by Novartis Pharmaceuticals
Corporation. No funding was provided for the authoring of this review. The authors received no honoraria related to the development of this publication.

Medical Writing. Medical writing support was funded by Novartis Pharmaceuticals Corporation. This medical writing support, including assisting authors with the development of the manuscript drafts and incorporation of comments, was provided by Meredith Whitaker, PhD, of Alphabet Health (New York, NY, USA), according to Good Publication Practice guidelines (https://www.ismpp.org/gpp3).

Authorship. All named authors meet the International Committee of Medical Journal Editors (ICMJE) criteria for authorship for this article, take responsibility for the integrity of the work as a whole, and have given their approval for this version to be published.

Authors' Contributions. All authors made substantial contributions to the manuscript concept/design, critically reviewed and revised the manuscript drafts, and provided final approval of the manuscript and enhanced content as submitted.

Disclosures. Robert K. Shin has received personal compensation as a consultant or speaker for Biogen, Bristol Myers Squibb, EMD Serono, Genentech, Mallinckrodt, Novartis, and Sanofi Genzyme. Kottil W. Rammohan has consulted for and received honorarium from Biogen, Novartis, Genzyme, Genentech, and EMD Serono, and received grants from Biogen, Novartis, EMD Serono, Genzyme, and Roche Genentech; no salary, stocks, or intellectual property. Mitzi J. Williams has received research support from EMD Serono, Genentech, and Novartis, and advisory and consulting fees from AbbVie, Biogen Idec, Bristol Myers Squibb, EMD Serono, Genentech, Novartis and Sanofi Genzyme.

Compliance with Ethics Guidelines. This article does not contain any studies with human participants or animals performed by any of the authors. 
Open Access. This article is licensed under a Creative Commons Attribution-NonCommercial 4.0 International License, which permits any non-commercial use, sharing, adaptation, distribution and reproduction in any medium or format, as long as you give appropriate credit to the original author(s) and the source, provide a link to the Creative Commons licence, and indicate if changes were made. The images or other third party material in this article are included in the article's Creative Commons licence, unless indicated otherwise in a credit line to the material. If material is not included in the article's Creative Commons licence and your intended use is not permitted by statutory regulation or exceeds the permitted use, you will need to obtain permission directly from the copyright holder. To view a copy of this licence, visit http://creativecommons.org/licenses/by$\mathrm{nc} / 4.0 /$.

\section{REFERENCES}

1. Centers for Disease Control and Prevention. Different COVID-19 vaccines. 2021. https://www.cdc. gov/coronavirus/2019-ncov/vaccines/differentvaccines.html. Accessed 28 May 2021.

2. Polack FP, Thomas SJ, Kitchin N, et al. Safety and efficacy of the BNT162b2 mRNA Covid-19 vaccine. N Engl J Med. 2020;383(27):2603-15.

3. Baden LR, El Sahly HM, Essink B, et al. Efficacy and safety of the mRNA-1273 SARS-CoV-2 vaccine. N Engl J Med. 2021;384(5):403-16.

4. Sadoff J, Gray G, Vandebosch A, et al. Safety and efficacy of single-dose Ad26.COV2.S vaccine against Covid-19. N Engl J Med. 2021;384(23):2187-201.

5. Miao L, Zhang Y, Huang L. mRNA vaccine for cancer immunotherapy. Mol Cancer. 2021;20(1):41.

6. Holder J. Tracking coronavirus vaccinations around the world. The New York Times; 2021. https://www. nytimes.com/interactive/2021/world/covidvaccinations-tracker.html. Accessed 18 June 2021.

7. Voysey M, Clemens SAC, Madhi SA, et al. Safety and efficacy of the ChAdOx1 nCoV-19 vaccine (AZD1222) against SARS-CoV-2: an interim analysis of four randomised controlled trials in Brazil, South Africa, and the UK. Lancet. 2021;397(10269): 99-111.
8. Walls AC, Park Y-J, Tortorici MA, Wall A, McGuire AT, Veesler D. Structure, function, and antigenicity of the SARS-CoV-2 spike glycoprotein. Cell. 2020;181(2):281-92.e6.

9. Barnes CO, Jette CA, Abernathy ME, et al. SARSCoV-2 neutralizing antibody structures inform therapeutic strategies. Nature. 2020;588(7839): 682-7.

10. Centers for Disease Control and Prevention. How influenza (Flu) vaccines are made. 2020. https:// www.cdc.gov/flu/prevent/how-fluvaccine-made. htm. Accessed 18 June 2021.

11. Filippi M, Capra R, Centonze D, et al. Therapeutic recommendations and seasonal influenza vaccine for multiple sclerosis patients in treatment with ocrelizumab: an expert consensus. J Neurol. 2021;268(4):1540-3.

12. Farez MF, Correale J, Armstrong MJ, et al. Practice guideline update summary: vaccine-preventable infections and immunization in multiple sclerosis: report of the Guideline Development, Dissemination, and Implementation Subcommittee of the American Academy of Neurology. Neurology. 2019;93(13):584-94.

13. Riva A, Barcella V, Benatti SV, et al. Vaccinations in patients with multiple sclerosis: a Delphi consensus statement. Mult Scler. 2021;27(3):347-59.

14. Centers for Disease Control and Prevention. Understanding how COVID-19 vaccines work. 2021. https://www.cdc.gov/coronavirus/2019ncov/vaccines/different-vaccines/how-they-work. html. Accessed 28 May 2021.

15. Pollard AJ, Bijker EM. A guide to vaccinology: from basic principles to new developments. Nat Rev Immunol. 2021;21(2):83-100.

16. Quinti I, Lougaris V, Milito C, et al. A possible role for B cells in COVID-19? Lesson from patients with agammaglobulinemia. J Allergy Clin Immunol. 2020;146(1):211-3.e4.

17. Hovey JG, Tolbert D, Howell D. Bruton's agammaglobulinemia and COVID-19. Cureus. 2020;12(11): e11701.

18. Jin H, Reed JC, Liu STH, et al. Three patients with X-linked agammaglobulinemia hospitalized for COVID-19 improved with convalescent plasma. J Allergy Clin Immunol Pract. 2020;8(10):3594-6. e3.

19. National Multiple Sclerosis Society. COVID-19 vaccine guidance for people living with MS. 2020 [updated May 21, 2021]. https://www. nationalmssociety.org/coronavirus-covid-19- 
information/multiple-sclerosis-and-coronavirus/ covid-19-vaccine-guidance. Accessed 28 May 2021.

20. COViMS Registry. The COViMS Database public data update. 2021. https://www.covims.org/ current-data. Accessed 16 June 2021.

21. van Kempen ZLE, Strijbis EMM, Al MMCT, et al. SARS-CoV-2 antibodies in adult patients with multiple sclerosis in the Amsterdam MS cohort. JAMA Neurol. 2021;78(7):880-2.

22. Achiron A, Mandel $M$, Dreyer-Alster $S$, et al. Humoral immune response to COVID-19 mRNA vaccine in patients with multiple sclerosis treated with high-efficacy disease-modifying therapies. Ther Adv Neurol Disord. 2021;14: 17562864211012836.

23. Kister I, Krogsgaard M, Mulligan MJ, et al. Preliminary results of ongoing, prospective study of antibody and T-cell responses to SARS-CoV-2 in patients with MS on ocrelizumab or other diseasemodifying therapies. Neurology. 2021;96(22): e2783-8.

24. Román GC, Gracia F, Torres A, Palacios A, Gracia K, Harris D. Acute transverse myelitis (ATM): clinical review of 43 patients with COVID-19-associated ATM and 3 post-vaccination ATM serious adverse events with the ChAdOx1 nCoV-19 vaccine (AZD1222). Front Immunol. 2021;12:879.
25. Bourdette D, Killestein J. Quelling public fears about Guillain-Barre syndrome and COVID-19 vaccination. Neurology. 2021;96:1021-2.

26. Patel SU, Khurram R, Lakhani A, Quirk B. Guillain-Barre syndrome following the first dose of the chimpanzee adenovirus-vectored COVID-19 vaccine, ChAdOx1. BMJ Case Rep. 2021;14(4):e242956.

27. Waheed S, Bayas A, Hindi F, Rizvi Z, Espinosa PS. Neurological complications of COVID-19: Guillain-Barre syndrome following Pfizer COVID-19 vaccine. Cureus. 2021;13(2):e13426.

28. Douxfils J, Favresse J, Dogné JM, et al. Hypotheses behind the very rare cases of thrombosis with thrombocytopenia syndrome after SARS-CoV-2 vaccination. Thromb Res. 2021;203:163-71.

29. Centers for Disease Control and Prevention. CDC recommends use of Johnson \& Johnson's Janssen COVID-19 vaccine resume. 2021. https://www.cdc. gov/coronavirus/2019-ncov/vaccines/safety/ jjupdate.html. Accessed 16 June 2021.

30. Ozonoff A, Nanishi E, Levy O. Bell's palsy and SARSCoV-2 vaccines. Lancet Infect Dis. 2021;21(4):450-2.

31. Giovannoni G, Smets I, Reyes S. MS minute: the COVID-19 vaccine and vaccine readiness in MS. Pract Neurol. 2021;77-81. https://practicalneuro logy.com/articles/2021-jan/ms-minute-the-covid19-vaccinevaccine-readiness-in-ms/pdf. 